\title{
Neck Circumference is Associated with Incidence of Angina Pectoris in a Large Community-Based Population
}

This article was published in the following Dove Press journal: Diabetes, Metabolic Syndrome and Obesity: Targets and Therapy

\author{
Bin Yan' \\ Hanzhi Du ${ }^{2}$ \\ Juan Zhao ${ }^{2}$ \\ $\mathrm{Di} W \mathrm{u}^{2}$ \\ Jie Wang ${ }^{2}$ \\ Guang Yang ${ }^{3}$ \\ Mengchang Wang ${ }^{2}$ \\ 'Department of Clinical Research \\ Centre, The First Affiliated Hospital of \\ Xi'an Jiaotong University, Xi'an, People's \\ Republic of China; ${ }^{2}$ Department of \\ Hematology, The First Affiliated Hospital \\ of Xi'an Jiaotong University, Xi'an, \\ People's Republic of China; ${ }^{3}$ Department \\ of Cardiology, Shaanxi Provincial People's \\ Hospital, Xi'an, People's Republic of \\ China
}

Correspondence: Mengchang Wang Department of Hematology,

The First Affiliated Hospital of Xi'an Jiaotong University, No. 277, Yanta West Road, Xi'an 71006I, People's Republic of China

Tel +86 I3772196075

Email swallow3956@sina.com
Background: Previous studies have found that neck circumference (NC) is associated with cardiovascular disease risk factors. This study investigated the relationship between NC and the incidence of angina pectoris (AP).

Methods: Altogether 4821 participants (2212 males and 2609 females) from the Sleep Heart Health Study (SHHS) with a mean age of $63.4 \pm 11.0$ years were selected in this study. Anthropometric measurements, including NC, waist circumference (WC), hip circumference (HC), and body mass index (BMI), were collected at baseline. AP was defined as the first occurrence between baseline and 2011. Linear and logistic regression analysis was used to explore the association between NC and incidences of AP.

Results: There was a significant difference in NC between AP and controls in both male $(41.1 \pm 3.1 \mathrm{~cm}$ vs $40.3 \pm 3.2 \mathrm{~cm} ; \mathrm{p}<0.001)$ and female $(35.2 \pm 3.1 \mathrm{~cm}$ vs $34.9 \pm 2.9 \mathrm{~cm} ; \mathrm{p}=0.006)$. Multivariable linear regression analysis showed that NC (every $\mathrm{cm}$ increase) was independently associated with the incidence of AP in both male (odds ratio [OR] 1.067; 95\% confidence interval [CI] 1.035-1.100; $\mathrm{p}<0.001$ ) and female (OR 1.067; 95\% CI 1.035-1.101; $\mathrm{p}<0.001)$.

Conclusion: NC was significantly associated with the incidence of AP in both male and female. The role of $\mathrm{NC}$ in the incidence of AP is worthy of further investigation.

Keywords: angina pectoris, neck circumference, SHHS, obesity, community-based population

\section{Introduction}

In recent years, the number of people living with overweight issues and obesity has been increasing around the world. ${ }^{1}$ In 2015 , a total of 107.7 million children and 603.7 million adults were considered obese. ${ }^{2}$ Common causes of obesity include poor eating habits, inactive lifestyle, sleep quality, genetics, endocrine system functions, psychological factors, and drugs. ${ }^{3}$ Obesity has become a medical condition that may further cause other diseases and health problems. ${ }^{4} \mathrm{~A}$ lot of studies have shown that obesity is a risk factor for cardiovascular disease (CVD), hypertension, diabetes mellitus, metabolic syndrome, and cancer. ${ }^{5-7}$ Anthropometric measurements, such as body mass index (BMI), waist circumference (WC), and hip circumference (HC), are typically used as indicators of body fat. Neck circumference (NC), which is correlated with the distribution of upper body subcutaneous adipose tissue, is also an anthropometric marker used to identify overweight and obese individuals. ${ }^{8}$ A previous study demonstrated that $\mathrm{NC}$ positively correlated 
with BMI and WC. ${ }^{9}$ In addition, $\mathrm{NC}$ was found to be more similar to visceral fat, which is more closely related to cardiovascular risk than subcutaneous fat. ${ }^{10}$ An increased $\mathrm{NC}$ was also found to be associated with cardiovascular risk factors, such as insulin resistance and metabolic syndrome. ${ }^{11}$ However, there is no evidence regarding the association between $\mathrm{NC}$ and the incidence of angina pectoris (AP). In the present study, we explore the role of NC and the incidence of AP using a large community-based population from the Sleep Heart Health Study (SHHS).

\section{Materials and Methods}

\section{Study Population}

All the participants in this study were selected from the SHHS (ClinicalTrials.gov Identifier: NCT00005275), which consisted of existing epidemiological studies (including the Atherosclerosis Risk in Communities Study, the Cardiovascular Health Study, the Framingham Offspring and Omni Study, the Strong Heart Study, Tucson Epidemiological Study of Obstructive Lung Disease, the cohort studies of respiratory disease in Tucson, and cohort studies of hypertension in New York). Details of the SHHS design and parent studies have been reported previously. ${ }^{12}$ Participants who had missing data regarding AP or NC, or had a history of AP were excluded (Figure 1).

\section{Anthropometric Measurements}

BMI was calculated as weight in kilograms divided by the square of the height in meters. WC was measured at the midpoint halfway between the inferior costal margin and the iliac crest. $\mathrm{HC}$ was measured at the greatest protrusion of the buttocks. NC was measured with the subject upright and head positioned in the Frankfort Horizontal Plane. An



Figure I Flow diagram of participant selection. inelastic tape measure was applied around the neck just inferior to the laryngeal prominence. In the present study, $\mathrm{NC}$ was further divided into quartiles in both male (quartile I: $\leq 38.5 \mathrm{~cm}$; quartile II: $38.6 \mathrm{~cm}-40.5 \mathrm{~cm}$; quartile III: $40.6 \mathrm{~cm} \mathrm{~cm}-42.7 \mathrm{~cm}$; quartile IV: $>42.7 \mathrm{~cm}$ ) and female (quartile I: $\leq 33.0 \mathrm{~cm}$; quartile II: $33.1 \mathrm{~cm}-35.0 \mathrm{~cm}$; quartile III: $35.1 \mathrm{~cm}-37.0 \mathrm{~cm}$; quartile IV: $>37.0 \mathrm{~cm}$ ).

AP incidences were extracted from discharge information at local hospitals according to cohort-specific protocols. The definition of AP was based on syndromes of coronary ischemia, ECG findings, exercises stress test, coronary angiography. AP was defined as the occurrence of the first episode during the average follow-up period of 11 years. The apnea-hypopnea index (AHI) was defined as all apnea and hypopnea episodes per hour of sleep accompanied by at least a $4 \%$ drop in oxygen saturation. The age, sex, race, education level, marital status, smoking status, alcohol use, prevalence of hypertension and diabetes, and polysomnography (PSG) data of participants were obtained from baseline examination of the SHHS.

\section{Statistical Analysis}

Independent sample $t$-tests and chi-square tests were performed to analyse the statistical difference in continuous variables and categorical variables, respectively. Univariate and multivariate logistic regression (or linear regression) analysis was used to analyses the association between anthropometric makers (NC, WC, HC, and BMI) and AP. After adjusting for age, sex, race, education level, marital status, smoking status, alcohol use, hypertension, diabetes mellitus, apnea hypopnea index (AHI), TC, HDL and TG, multivariable logistic regression (or linear regression) was performed to identify independent risk factors and to estimate the odds ratio (OR) and $95 \%$ confidence interval (CI). Interaction terms were also constructed between NC and AHI. P-values $<0.05$ were considered statistically significant. All statistical analyses were performed using SPSS, version 24.0 (SPSS Inc., Chicago, IL).

\section{Results}

\section{Participants' Characteristics}

The characteristics of the participants with or without AP are shown in Table 1. In this study, 2212 males and 2609 females with a mean age of $63.4 \pm 11.0$ years were included. Individuals with AP were older, more likely to be married and of Caucasian descent in both male and female. Participants with AP also had longer education 
experience, larger $\mathrm{NC}, \mathrm{WC}$, and $\mathrm{HC}$, as well as higher BMI in both male and female. In addition, the correlation coefficients (Pearson's correlations) among different anthropometric measurements are showed in Supplement Table 1.

\section{$\mathrm{NC}$ and $\mathrm{AP}$}

$\mathrm{NC}$ in participants with AP was significantly larger than those without AP in male $(41.1 \pm 3.1 \mathrm{~cm}$ vs $40.3 \pm 3.2 \mathrm{~cm}$; $\mathrm{P}<0.001)$ and female $(35.2 \pm 3.1 \mathrm{~cm}$ vs $34.9 \pm 2.9 \mathrm{~cm}$; $\mathrm{P}=0.006$ ). After adjusting for age, race, educational level, marital status, smoking status, alcohol use, hypertension, diabetes mellitus, AHI, TC, HDL and TG, NC (increased $1 \mathrm{~cm}$ ) was positively associated with the incidence of AP in male (OR 1.067; 95\% CI 1.035-1.100; $\mathrm{P}<0.001$ ) and female (OR 1.067; 95\% CI 1.035-1.101; $\mathrm{P}<0.001)$ (Table 2).

$\mathrm{NC}$ was further divided into quartiles in male and female. Participants in the fourth, third, and second quartile were more likely to have a higher incidence of AP than those in the first quartile in both male $(53.8 \%, 49.6 \%$, $46.2 \%$ vs $38.0 \%$, respectively) and female (39.4\%, $42.7 \%, 41.0 \%$ vs $44.1 \%$, respectively) (Table 3 ). The incidence of AP stratified by BMI and AHI in different $\mathrm{NC}$ quartiles is shown in Figure 2. Multivariable logistic regression showed that the fourth quartile (OR 1.818; 95\% CI 1.397-2.366; $\mathrm{P}<0.001$ ), third quartile (OR 1.544; 95\% CI 1.183-2.014; $\mathrm{P}=0.001$ ), and second quartile (OR 1.308; 95\% CI 1.015-1.685; $\mathrm{P}=0.037$ ) of $\mathrm{NC}$ were risk factors for AP incidence when compared to the first quartile in males. Females in the fourth quartile of $\mathrm{NC}$ also had an increased risk of AP (OR 1.513; 95\% CI 1.161-1.972; $\mathrm{P}=0.002$ ) (Table 3). We further explored the interactions between $\mathrm{NC}$ and $\mathrm{AHI}$ in the final multivariate logistic regression model. No significant interactions were found in these analyses.

\section{$B M I, W C, H C$, and $A P$}

We also investigated the relationship between BMI, WC, $\mathrm{HC}$, and AP. Multivariate linear regression analysis revealed that BMI (OR 1.055; 95\% CI 1.031-1.079; $\mathrm{P}<0.001$ ) and WC (OR 1.024; 95\% CI 1.014-1.033; $\mathrm{P}<0.001$ ) were associated with AP incidence in male. In female, BMI (OR 1.054; 95\% CI 1.037-1.072; $\mathrm{P}<0.001$ ), WC (OR 1.047; 95\% CI 1.040-1.054; $\mathrm{P}<0.001$ ), and HC (OR 1.021; 95\% CI 1.013-1.029; $\mathrm{P}<0.001$ ) were also closely related to the occurrence of AP (Table 2).

\section{Discussion}

Obesity is a complex disease and usually increases the risk of diabetes mellitus, hypertension, metabolic syndrome, CVD, sleep disorder breathing (SDB), and cancer. ${ }^{5-7,13}$ BMI, a measure based on height and weight, was used as an indicator for body fat. A BMI greater or equal to $30.0 \mathrm{~kg} / \mathrm{m}^{2}$ was defined as obese, while a BMI between $25.0 \mathrm{~kg} / \mathrm{m}^{2}$ and $29.9 \mathrm{~kg} / \mathrm{m}^{2}$ was defined as overweight. $\mathrm{WC}$ and $\mathrm{HC}$ were also used to evaluate subcutaneous fat. $\mathrm{NC}$, a relatively novel method in identifying obesity, has been found to be a useful screening tool for cardiovascular risk. ${ }^{14}$ Compared to traditional anthropometric measures, such as BMI, WC, and $\mathrm{HC}, \mathrm{NC}$ has been found to be more closely related to visceral fat, which is strongly associated with cardio-metabolic risks than subcutaneous fat. ${ }^{9,15}$ In addition, NC was less susceptible to the effects of meal and health conditions and could be measured easily in winter compared with $\mathrm{WC}$ and $\mathrm{HC} .{ }^{14}$ However, there is little evidence about the relationship between NC and AP. In the present study, we investigated the association between NC and AP incidence using a large communitybased population. Our results demonstrated that increased $\mathrm{NC}$ was a risk factor for the occurrence of AP in both male and female.

AP is a symptom of coronary heart disease and is usually caused by cardiac ischemia. ${ }^{16,17}$ Age, smoking, high blood pressure, hyperlipidemia, diabetes mellitus, history of coronary artery disease, stress, and sleeping habits are common AP risk factors. In addition, obesity is also a vital factor in the development of AP. ${ }^{18}$ Previous studies have shown that $\mathrm{NC}$ is associated with cardiovascular risk factors, such as obesity, systolic blood pressure, cholesterol, hyperuricemia, carotid intima-media thickness, and metabolic syndrome. ${ }^{11,19-22}$ Zhang et al also found that NC was correlated with heart failure in people without $\mathrm{SDB}^{23}$ In this study, we explored the role of $\mathrm{NC}$ in the incidence of $\mathrm{AP}$ and found that the fourth quartile of $\mathrm{NC}$ had a substantially higher proportion of participants with AP compared to those in the first quartile in both male and female. These results indicate that individuals with a large $\mathrm{NC}$ tended to have an increased risk of AP and that $\mathrm{NC}$ may be an essential anthropometric measurement for screening people with AP.

Many studies have shown that large $\mathrm{NC}$ was a predictor for SDB. ${ }^{24}$ Moreover, SDB was also a risk factor for CVD. ${ }^{25,26} \mathrm{AHI}$ may be a confounding factor 
Table I Characteristics of the Study Subjects

\begin{tabular}{|c|c|c|c|c|c|c|c|}
\hline \multirow[t]{2}{*}{ Variables } & \multirow{2}{*}{$\begin{array}{l}\text { Total } \\
(n=482 I)\end{array}$} & \multicolumn{2}{|c|}{ Men $(n=2212)$} & \multirow[b]{2}{*}{$P$ value } & \multicolumn{2}{|c|}{ Women $(n=2609)$} & \multirow[b]{2}{*}{$P$ value } \\
\hline & & $\begin{array}{l}\text { Angina } \\
(n=1035)\end{array}$ & $\begin{array}{l}\text { Non-Angina } \\
(n=\mid 177)\end{array}$ & & $\begin{array}{l}\text { Angina } \\
(n=1086)\end{array}$ & $\begin{array}{l}\text { Non-Angina } \\
(n=1523)\end{array}$ & \\
\hline Age, years & $63.4 \pm 11.0$ & $64.5 \pm 7.1$ & $62.2 \pm 12.9$ & $<0.001$ & $63.8 \pm 7.7$ & $63.1 \pm 13.3$ & $<0.001$ \\
\hline Race, n (\%) & & & & $<0.001$ & & & $<0.001$ \\
\hline White & $4182(86.7)$ & $999(96.5)$ & $939(79.8)$ & - & 1040 & I $204(79.1)$ & - \\
\hline Black & $316(6.6)$ & $29(2.8)$ & $99(8.4)$ & - & $42(3.9)$ & $146(9.6)$ & - \\
\hline Other & $323(6.7)$ & $7(0.7)$ & $139(11.8)$ & - & $4(0.4)$ & $173(11.4)$ & - \\
\hline Education, n (\%) & & & & 0.001 & & & $<0.001$ \\
\hline$\leq 15$, years & $2759(63.1)$ & $538(52.4)$ & 591 (59.9) & - & $690(63.8)$ & $940(73.7)$ & - \\
\hline$>15$, years & $1610(36.9)$ & $489(47.6)$ & $395(40.1)$ & - & $391(36.2)$ & $335(26.3)$ & - \\
\hline Marital Status, n (\%) & & & & $<0.001$ & & & $<0.001$ \\
\hline Married & 3778 (79.8) & $954(92.4)$ & $980(86.0)$ & - & $867(80.0)$ & 977 (65.9) & - \\
\hline Other & $959(20.2)$ & $78(7.6)$ & $159(14.0)$ & - & $217(20.0)$ & 505 & - \\
\hline $\begin{array}{l}\text { Smoking status, } \\
\text { n (\%) }\end{array}$ & & & & 0.008 & & & 0.590 \\
\hline Current smoker & $478(9.9)$ & $98(9.5)$ & $136(11.6)$ & - & $109(10.1)$ & 135 (8.9) & - \\
\hline Former smoker & $2093(43.5)$ & $598(57.9)$ & $603(51.3)$ & - & $371(34.2)$ & $521(34.3)$ & - \\
\hline Never smoker & $2240(46.6)$ & $337(32.6)$ & $436(37.1)$ & - & $604(55.7)$ & $863(56.8)$ & - \\
\hline Alcohol use, n (\%) & & & & 0.200 & & & 0.731 \\
\hline $\begin{array}{l}\text { At least I drink } \\
\text { per day }\end{array}$ & $1952(43.4)$ & $546(52.9)$ & $572(55.8)$ & - & $367(33.8)$ & $467(34.6)$ & - \\
\hline None & $2543(56.6)$ & $487(47.1)$ & $454(44.2)$ & - & $718(66.2)$ & $884(65.4)$ & - \\
\hline $\begin{array}{l}\text { Body mass index, } \\
\text { n (\%) }\end{array}$ & & & & $<0.001$ & & & 0.001 \\
\hline$\geq 30, \mathrm{~kg} / \mathrm{m} 2$ & 1489 (31.2) & $357(34.6)$ & $329(28.1)$ & - & $379(35.1)$ & $424(28.4)$ & - \\
\hline $25-29.9, \mathrm{~kg} / \mathrm{m} 2$ & $2024(42.4)$ & $501(48.5)$ & $563(48.2)$ & - & $390(36.1)$ & $570(38.2)$ & - \\
\hline $18.5-24.9, \mathrm{~kg} / \mathrm{m} 2$ & $1262(26.4)$ & $175(16.9)$ & $277(23.7)$ & - & $3 I I(28.8)$ & $499(33.4)$ & - \\
\hline $\begin{array}{l}\text { Neck } \\
\text { circumference, cm }\end{array}$ & $37.6 \pm 4.2$ & $4 I . I \pm 3 . I$ & $40.3 \pm 3.2$ & $<0.001$ & $35.2 \pm 3.1$ & $34.9 \pm 2.9$ & 0.006 \\
\hline $\begin{array}{l}\text { Waist } \\
\text { circumference, cm }\end{array}$ & $97.3 \pm 13.7$ & $102.0 \pm 12.3$ & $92.2 \pm 28.1$ & $<0.001$ & $98.1 \pm 14.5$ & $91.2 \pm 14.8$ & $<0.001$ \\
\hline $\begin{array}{l}\text { Hip } \\
\text { circumference, } \mathrm{cm}\end{array}$ & $105.3 \pm 10.4$ & $104.1 \pm 10.5$ & $96.0 \pm 28.7$ & $<0.001$ & $107.4 \pm 11.2$ & $105.5 \pm 11.9$ & $<0.001$ \\
\hline Hypertension, n (\%) & $1859(38.6)$ & $413(39.9)$ & $449(38.1)$ & 0.407 & $4 I I(37.8)$ & $586(38.5)$ & 0.775 \\
\hline $\begin{array}{l}\text { Diabetes mellitus, } \\
\mathrm{n}(\%)\end{array}$ & $326(6.8)$ & $84(8.1)$ & $87(7.4)$ & 0.525 & 71 (6.5) & $84(5.5)$ & 0.276 \\
\hline AHI, n (\%) & & & & 0.095 & & & 0.782 \\
\hline$\geq 30.0$, events/h & $348(7.2)$ & $115(11.1)$ & $125(10.6)$ & - & $45(4.1)$ & $63(4.1)$ & - \\
\hline 15.0-29.9, events/h & $644(13.4)$ & $202(19.5)$ & $207(17.6)$ & - & $96(8.8)$ & $139(9.1)$ & - \\
\hline 5.0-14.9, events/h & 1457 (30.2) & $370(35.7)$ & $389(33.1)$ & - & $302(27.8)$ & $396(26.0)$ & - \\
\hline$<5.0$, events $/ \mathrm{h}$ & $2372(49.2)$ & $348(33.6)$ & 456 (38.7) & - & $643(59.2)$ & $925(60.7)$ & - \\
\hline
\end{tabular}


Table I (Continued).

\begin{tabular}{|c|c|c|c|c|c|c|c|}
\hline \multirow[t]{2}{*}{ Variables } & \multirow{2}{*}{$\begin{array}{l}\text { Total } \\
(n=482 I)\end{array}$} & \multicolumn{2}{|c|}{ Men $(n=22 \mid 2)$} & \multirow[b]{2}{*}{$P$ value } & \multicolumn{2}{|c|}{ Women $(n=2609)$} & \multirow[b]{2}{*}{$P$ value } \\
\hline & & $\begin{array}{l}\text { Angina } \\
(n=1035)\end{array}$ & $\begin{array}{l}\text { Non-Angina } \\
(n=1 \mid 77)\end{array}$ & & $\begin{array}{l}\text { Angina } \\
(n=1086)\end{array}$ & $\begin{array}{l}\text { Non-Angina } \\
(n=1523)\end{array}$ & \\
\hline SBP & $125.2 \pm 18.2$ & $124.1 \pm 17.3$ & $127.9 \pm 17.1$ & $<0.001$ & $122.2 \pm 18.7$ & $126.1 \pm 18.8$ & $<0.001$ \\
\hline DBP & $72.4 \pm 10.8$ & $72.0 \pm 9.9$ & $75.8 \pm 11.5$ & $<0.001$ & $69.4 \pm 9.5$ & $72.2 \pm 11.0$ & $<0.001$ \\
\hline TC & $206.8 \pm 38.4$ & $199.5 \pm 34.9$ & $202.4 \pm 38.5$ & 0.071 & $215.5 \pm 38.5$ & $209.0 \pm 38.3$ & $<0.001$ \\
\hline HDL & $50.7 \pm 15.8$ & $43.7 \pm 12.8$ & $43.9 \pm 11.4$ & 0.771 & $58.2 \pm 17.8$ & $55.4 \pm 14.5$ & $<0.001$ \\
\hline TG & $151.4 \pm 100.6$ & $|47.| \pm 98 . \mid$ & $165.4 \pm 115.7$ & $<0.001$ & $150.9 \pm 92.9$ & $144.3 \pm 95.0$ & 0.090 \\
\hline
\end{tabular}

Notes: Results are presented as mean \pm standard deviation or $\mathrm{n}(\%)$. The $\mathrm{P}$ values represent the difference between two groups.

Abbreviations: AHI, apnea hypopnea index; DBP, diastolic blood pressure; HDL, high-density lipoprotein; SBP, systolic blood pressure; TC, total cholesterol; TG, triglyceride.

Table 2 ORs and 95\% Cls for Neck Circumference Associated with Angina Pectoris in Male and Female

\begin{tabular}{|c|c|c|c|c|c|c|}
\hline $\mathbf{A P}$ & Univariate Models & & Multivariable Adjusted $^{a}$ & & Multivariable Adjusted ${ }^{\mathbf{b}}$ & \\
\hline Male (per I SD) & OR $(95 \% \mathrm{Cl})$ & $P$ & OR $(95 \% \mathrm{Cl})$ & $P$ & OR $(95 \% \mathrm{Cl})$ & $P$ \\
\hline Neck circumference & $1.073(1.044-1.102)$ & $<0.001$ & 1.067 (1.035-1.099) & $<0.001$ & $1.086(1.051-1.121)$ & $<0.001$ \\
\hline Waist circumference & $1.025(1.017-1.033)$ & $<0.001$ & $1.023(1.014-1.032)$ & 0.001 & $1.03 \mathrm{I}(\mathrm{I} .02 \mathrm{I}-\mathrm{I} .04 \mathrm{I})$ & $<0.001$ \\
\hline Hip circumference & $1.011(1.001-1.020)$ & 0.031 & $1.007(0.997-1.018)$ & 0.181 & $1.014(1.002-1.026)$ & 0.020 \\
\hline BMI & $1.045(1.025-1.065)$ & $<0.001$ & $1.053(1.031-1.076)$ & $<0.001$ & $1.070(1.045-1.096)$ & $<0.001$ \\
\hline Female (per I SD) & OR $(95 \% \mathrm{Cl})$ & $P$ & OR $(95 \% \mathrm{Cl})$ & $P$ & OR $(95 \% \mathrm{Cl})$ & $P$ \\
\hline Neck circumference & $1.037(1.010-1.064)$ & 0.006 & $1.062(1.031-1.094)$ & $<0.001$ & $1.090(1.054-1.127)$ & $<0.001$ \\
\hline Waist circumference & $1.032(1.027-1.038)$ & $<0.001$ & $1.043(1.036-1.051)$ & $<0.001$ & $1.050(1.042-1.058)$ & $<0.001$ \\
\hline Hip circumference & $1.014(1.007-1.021)$ & $<0.001$ & $1.019(1.011-1.027)$ & $<0.001$ & $1.027(1.018-1.035)$ & $<0.001$ \\
\hline BMI & $1.028(1.014-1.042)$ & $<0.001$ & $1.049(1.033-1.066)$ & $<0.001$ & $1.067(1.048-1.086)$ & $<0.001$ \\
\hline
\end{tabular}

Notes: ${ }^{a}$ Adjusted for age, race, education, marry status, smoking status, alcohol use, hypertension and diabetes mellitus. ${ }^{b}$ Adjusted for a+ AHI, TC, HDL and TG.

Abbreviations: AHI, apnea hypopnea index; AP, angina pectoris; BMI, body mass index; $95 \% \mathrm{Cl}, 95 \%$ confidence interval; HDL, high-density lipoprotein; OR, odds ratio; TC, total cholesterol; TG, triglyceride; SD, standard deviation.

Table 3 ORs and 95\% Cls for Neck Circumference Quartiles Associated with Angina Pectoris in Male and Female

\begin{tabular}{|c|c|c|c|c|c|c|}
\hline AP & & & Multivariable Adjusted $^{a}$ & & Multivariable Adjusted $^{\mathbf{b}}$ & \\
\hline Male (per I cm) & Persons $(\mathrm{N})$ & Events, n (\%) & OR $(95 \% \mathrm{Cl})$ & $P$ & OR $(95 \% \mathrm{Cl})$ & $P$ \\
\hline Neck circumference & 2212 & $1035(46.8)$ & & & & \\
\hline Q4 (>42.7cm) & 552 & $297(53.8)$ & $1.818(1.397-2.366)$ & $<0.001$ & $2.096(1.580-2.78 \mathrm{I})$ & $<0.001$ \\
\hline Q3 $(40.6 \mathrm{~cm}-42.7 \mathrm{~cm})$ & 502 & $249(49.6)$ & $1.544(1.183-2.014)$ & 0.001 & 1.645 (1.246-2.170) & $<0.001$ \\
\hline Q2 $(38.62 \mathrm{~cm}-40.5 \mathrm{~cm})$ & 595 & $275(46.2)$ & $1.308(1.015-1.685)$ & 0.038 & 1.346 (I.037-I.747) & 0.026 \\
\hline QI $(\leq 38.5 \mathrm{~cm})$ & 563 & $214(38.0)$ & I & & I & \\
\hline Female (per I cm) & & & OR $(95 \% \mathrm{Cl})$ & $P$ & OR $(95 \% \mathrm{Cl})$ & $\mathrm{P}$ \\
\hline Neck circumference & 2609 & $1086(41.6)$ & & & & \\
\hline Q4 (>37.0cm) & 522 & $230(44.1)$ & $1.473(1.14 \mid-1.902)$ & 0.003 & $1.74 \mathrm{I}(\mathrm{I} .3 \mathrm{II}-2.3 \mathrm{II})$ & $<0.001$ \\
\hline Q3 $(35.1 \mathrm{~cm}-37.0 \mathrm{~cm})$ & 590 & $242(4 I .0)$ & $1.103(0.869-1.400)$ & 0.420 & $1.197(0.927-1.546)$ & 0.167 \\
\hline Q2 $(33.1 \mathrm{~cm}-35.0 \mathrm{~cm})$ & 745 & $318(42.7)$ & $1.098(0.879-1.372)$ & 0.409 & $1.205(0.953-1.525)$ & 0.120 \\
\hline QI $(\leq 33.0 \mathrm{~cm})$ & 752 & $296(39.4)$ & I & & I & \\
\hline
\end{tabular}

Notes: ${ }^{a}$ Adjusted for age, race, education, marry status, smoking status, alcohol use, hypertension and diabetes mellitus. ${ }^{b}$ Adjusted for a+ AHI, TC, HDL and TG.

Abbreviations: AHI, apnea hypopnea index; AP, angina pectoris; $95 \% \mathrm{Cl}, 95 \%$ confidence interval; $\mathrm{HDL}$, high-density lipoprotein; OR, odds ratio; TC, total cholesterol; TG, triglyceride. 

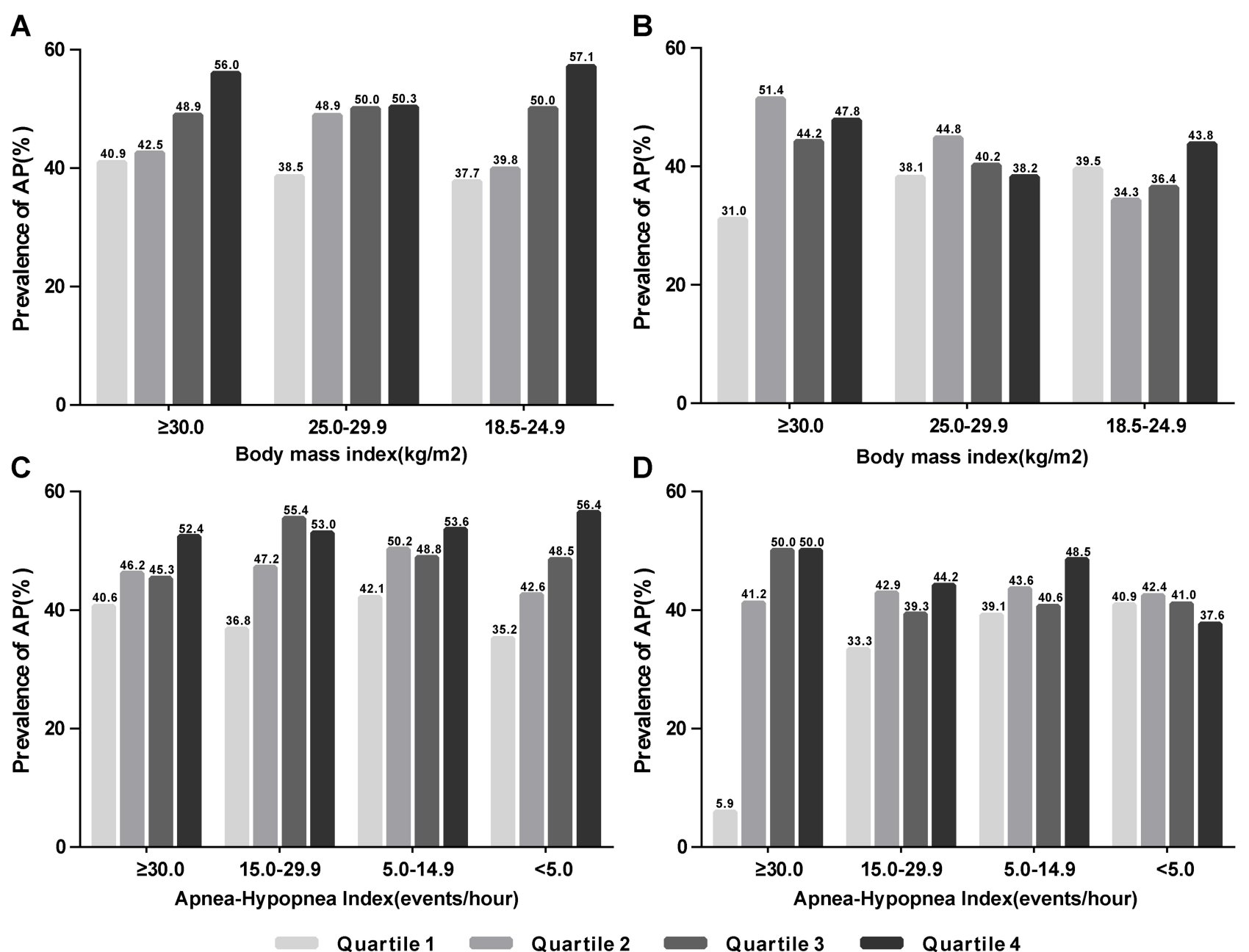

Figure 2 Distribution of AP incidence in NC quartiles stratified by BMI and AHI among males (quartile I $\leq 38.5 \mathrm{~cm}$; quartile II: $38.6 \mathrm{~cm}-40.5 \mathrm{~cm}$; quartile III: $40.6 \mathrm{~cm}-$ $42.7 \mathrm{~cm}$; quartile IV: $>42.7 \mathrm{~cm}$ ) and females (quartile I $\leq 33.0 \mathrm{~cm}$; quartile II: $33.1 \mathrm{~cm}-35.0 \mathrm{~cm}$; quartile III: $35.1 \mathrm{~cm}-37.0 \mathrm{~cm}$; quartile IV: $>37.0 \mathrm{~cm}$ ). (A) stratified by BMI in Male; (B) stratified by BMI in Female; (C) stratified by AHI in Male; (D) stratified by AHI in Female.

Abbreviations: $\mathrm{AHI}$, apnea hypopnea index; AP, angina pectoris; $\mathrm{BMI}$, body mass index; NC, neck circumference.

between NC and CVD risk factors. ${ }^{10}$ In our study, we investigated the distribution of $\mathrm{AP}$ in different $\mathrm{NC}$ quartiles stratified by AHI. In male, there was a noticeably high incidence of AP in individuals with larger $\mathrm{NC}$ in each subgroup of AHI. This phenomenon is less pronounced in female than in male. We also adjusted AHI in the final multivariate logistic regression analysis. Interaction analysis was also performed between NC and AHI when investigating the role of $\mathrm{NC}$ in the incidence of AP. No significant interaction was found in these analyses. The results indicated that $\mathrm{NC}$ was significantly associated with AP incidence irrespective of AHI level. Besides, the incidence of $\mathrm{AP}$ in $\mathrm{NC}$ quartiles stratified by BMI was also different. Males with a large NC obviously tended to have a high incidence of AP in different BMI categories but the trend was not observed in females.
The mechanisms of NC in the incidence of AP remain unknown. However, upper body fat, usually evaluated by $\mathrm{NC}$, is closely related to the level of systemic free fatty acids (FFA). ${ }^{10,27}$ Meanwhile, systemic FFA has been found to be associated with insulin resistance, oxidative stress, triglyceride production, and vascular injury, which are risk factors for $\mathrm{CVD} .^{28} \mathrm{In}$ addition, $\mathrm{NC}$ was also found to be an anthropometric marker for visceral fat, which was significantly correlated with cardiovascular risk. ${ }^{29}$ Therefore, NC may be an indicator of the occurrence of AP.

There are several strengths and limitations to the present study. This is the first study to explore the relationship between NC and AP incidence and because our data were based on a community study, our findings can be generalized to a certain extent. However, some limitations still 
exist. The dataset of SHHS lacked most of the follow-up time of the first AP episode; thus, we could not investigate the association between $\mathrm{NC}$ and $\mathrm{AP}$ using the Cox proportional hazards regression models. Besides, the sample size is relatively small in the stratified analysis. In addition, the majority of participants were Caucasian; therefore, our results cannot be generalized to all ethnic groups.

\section{Conclusion}

In this study, we investigated the association of $\mathrm{NC}$ with AP incidence. Our results showed that individuals with larger NC had an increased risk of AP incidence in both male and female. Thus, NC may be a marker to predict the occurrence of AP.

\section{Clinical Trial Registration}

Sleep Heart Health Study Data Coordinating Center; URL: https:/clinicaltrials.gov/ct2/show/NCT00005275?term= NCT00005275\&rank=1ClinicalTrials.gov Identifier: NCT00005275.

\section{Acknowledgments}

We appreciate the Brigham and Women's Hospital for sharing the Datasets of Sleep Heart Health Study (SHHS). SHHS is particularly grateful to the members of these cohorts who agreed to participate in SHHS as well. SHHS further recognizes all of the investigators and staff who have contributed to its success. A list of SHHS investigators, staff and their participating institutions are available on the SHHS website, www.jhucct.com/shhs.

\section{Author Contributions}

All authors made a significant contribution to the work reported, whether that is in the conception, study design, execution, acquisition of data, analysis and interpretation, or in all these areas; took part in drafting, revising or critically reviewing the article; gave final approval of the version to be published; have agreed on the journal to which the article has been submitted; and agree to be accountable for all aspects of the work.

\section{Funding}

This research was supported by the National Natural Science Foundation of China (Grant number: No. 81071952) and the Clinical Research Award of the First Affiliated Hospital of Xi'an Jiaotong University, China (No.XJTU1AF-CRF-2019-022).

\section{Disclosure}

The authors declare that they have no conflicts of interest for this work.

\section{References}

1. Lozano R, Naghavi M, Foreman K, et al. Global and regional mortality from 235 causes of death for 20 age groups in 1990 and 2010: a systematic analysis for the global burden of disease study 2010. Lancet. 2012;380 (9859):2095-2128. doi:10.1016/S0140-6736(12)61728-0

2. Zen V, Fuchs FD, Wainstein MV, et al. Neck circumference and central obesity are independent predictors of coronary artery disease in patients undergoing coronary angiography. Am J Cardiovasc Dis. 2012;2(4):323-330.

3. Apovian CM. Obesity: definition, comorbidities, causes, and burden. Am J Manag Care. 2016;22(7 Suppl):s176-85.

4. Williams EP, Mesidor M, Winters K, Dubbert PM, Wyatt SB. Overweight and obesity: prevalence, consequences, and causes of a growing public health problem. Curr Obes Rep. 2015;4 (3):363-370. doi:10.1007/s13679-015-0169-4

5. Seravalle G, Grassi G. Obesity and hypertension. Pharmacol Res. 2017;122:1-7. doi:10.1016/j.phrs.2017.05.013

6. Parto P, Lavie CJ. Obesity and cardiovascularDiseases. Curr Probl Cardiol. 2017;42(11):376-394. doi:10.1016/j.cpcardiol.2017.04.004

7. Engin A. The definition and prevalence of obesity and metabolic syndrome. Adv Exp Med Biol. 2017;960:1-17.

8. Zhang J, Gong Z, Li R, et al. Influence of lung function and sleep-disordered breathing on stroke: a community-based study. Eur J Neurol. 2018;25(11):1307-e112. doi:10.1111/ene.13722

9. Joshipura K, Munoz-Torres F, Vergara J, Palacios C, Perez CM. Neck circumference may be a better alternative to standard anthropometric measures. J Diabetes Res. 2016;2016:6058916. doi:10.1155/2016/ 6058916

10. Preis SR, Massaro JM, Hoffmann U, et al. Neck circumference as a novel measure of cardiometabolic risk: the framingham heart study. J Clin Endocrinol Metab. 2010;95(8):3701-3710. doi:10.1210/ jc.2009-1779

11. Luo Y, Ma X, Shen Y, et al. Neck circumference as an effective measure for identifying cardio-metabolic syndrome: a comparison with waist circumference. Endocrine. 2017;55(3):822-830. doi:10.1007/s12020-016-1151-y

12. Quan SF, Howard BV, Iber C, et al. The sleep heart health study: design, rationale, and methods. Sleep. 1997;20(12):1077-1085.

13. Leinum CJ, Dopp JM, Morgan BJ. Sleep-disordered breathing and obesity: pathophysiology, complications, and treatment. Nutr Clin Pract. 2009;24(6):675-687. doi:10.1177/0884533609351532

14. Pei X, Liu L, Imam MU, et al. Neck circumference may be a valuable tool for screening individuals with obesity: findings from a young Chinese population and a meta-analysis. BMC Public Health. 2018;18(1):529. doi:10.1186/s12889-018-5448-Z

15. Zhou JY, Ge H, Zhu MF, et al. Neck circumference as an independent predictive contributor to cardio-metabolic syndrome. Cardiovasc Diabetol. 2013;12(1):76. doi:10.1186/1475-2840-12-76

16. Thadani U. Management of stable angina - current guidelines: a critical appraisal. Cardiovasc Drugs Ther. 2016;30(4):419-426. doi:10.1007/s10557-016-6681-2

17. Hemingway H, Langenberg C, Damant J, Frost C, Pyorala K, BarrettConnor E. Prevalence of angina in women versus men: a systematic review and meta-analysis of international variations across 31 countries. Circulation. 2008;117(12):1526-1536. doi:10.1161/ CIRCULATIONAHA.107.720953

18. Schmidt M, Botker HE, Pedersen L, Sorensen HT. Young adulthood obesity and risk of acute coronary syndromes, stable angina pectoris, and congestive heart failure: a 36-year cohort study. Ann Epidemiol. 2014;24(5):356-61 e1. doi:10.1016/j.annepidem.2014.01.011 
19. Famodu OA, Barr ML, Colby SE, et al. Neck circumference positively relates to cardiovascular risk factors in college students. Int J Environ Res Public Health. 2018;15:7. doi:10.3390/ ijerph15071480

20. Jiang J, Cui J, Yang X, et al. Neck circumference, a novel indicator for hyperuricemia. Front Physiol. 2017;8:965. doi:10.3389/ fphys.2017.00965

21. Baena CP, Lotufo PA, Santos IS, et al. Neck circumference is associated with carotid intimal-media thickness but not with coronary artery calcium: results from the ELSA-Brasil. Nutr Metab Cardiovasc Dis. 2016;26(3):216-222. doi:10.1016/j. numecd.2016.01.004

22. Ben-Noun LL, Laor A. Relationship between changes in neck circumference and cardiovascular risk factors. Exp Clin Cardiol. 2006;11(1):14-20.

23. Zhang J, Guo Q, Peng L, et al. The association of neck circumference with incident congestive heart failure and coronary heart disease mortality in a community-based population with or without sleep-disordered breathing. BMC Cardiovasc Disord. 2018;18 (1):108. doi:10.1186/s12872-018-0846-9

24. Caffo B, Diener-West M, Punjabi NM, Samet J. A novel approach to prediction of mild obstructive sleep disordered breathing in a population-based sample: the sleep heart health study. Sleep. 2010;33(12):1641-1648. doi:10.1093/sleep/33.12.1641
25. Kendzerska T, Gershon AS, Hawker G, Leung RS, Tomlinson G. Obstructive sleep apnea and risk of cardiovascular events and all-cause mortality: a decade-long historical cohort study. PLoS Med. 2014;11(2):e1001599. doi:10.1371/journal.pmed.1001599

26. Chami HA, Resnick HE, Quan SF, Gottlieb DJ. Association of incident cardiovascular disease with progression of sleep-disordered breathing. Circulation. 2011;123(12):1280-1286. doi:10.1161/ CIRCULATIONAHA.110.974022

27. Nielsen S, Guo Z, Johnson CM, Hensrud DD, Jensen MD. Splanchnic lipolysis in human obesity. J Clin Invest. 2004;113 (11):1582-1588. doi:10.1172/JCI21047

28. Santosa S, Jensen MD. Why are we shaped differently, and why does it matter? Am J Physiol Endocrinol Metab. 2008;295(3):E531-5. doi:10.1152/ajpendo.90357.2008

29. Preis SR, Pencina MJ, D’Agostino RB, Meigs JB, Vasan RS, Fox CS. Neck circumference and the development of cardiovascular disease risk factors in the framingham heart study. Diabetes Care. 2013;36 (1):e3. doi: $10.2337 /$ dc12-0738

\section{Publish your work in this journal}

Diabetes, Metabolic Syndrome and Obesity: Targets and Therapy is an international, peer-reviewed open-access journal committed to the rapid publication of the latest laboratory and clinical findings in the fields of diabetes, metabolic syndrome and obesity research. Original research, review, case reports, hypothesis formation, expert opinion and commentaries are all considered for publication. The manuscript management system is completely online and includes a very quick and fair peer-review system, which is all easy to use. Visit http://www.dovepress.com/testimonials.php to read real quotes from published authors.

Submit your manuscript here: https://www.dovepress.com/diabetes-metabolic-syndrome-and-obesity-targets-and-therapy-journal 